\title{
Reflexiones éticas desde el confucionismo: la mujer
}

\section{Ethical reflections from confucianism: the woman}

\author{
Martha Tarasco Michel, * José Enrique Gómez Álvarez **
}

https://doi.org/10.36105/mye.2020v31n2.06

\section{Resumen}

El artículo resume la posición o rol de la mujer en el confucionismo clásico. Parte de los textos clásicos del conficionismo, buscando elementos entresacados de los textos que den pistas de la concepción y trato de la mujer. El confucionismo como filosofía práctica se convierte en una doctrina ética fundada fuertemente en la virtud, con miras a mejorar al hombre individual y a la sociedad en su conjunto. La virtud es el eje de las acciones del individuo y del Estado. En el Libro de los Ritos se describen detalles del rol de la mujer en la sociedad, el cual prácticamente se reduce a su papel de esposa y madre. La subordinación de la mujer hacia el hombre en su toma de decisiones queda claramente establecido en los textos. En conclusión, en el confucionismo la relación de parentesco es la que logra el género de la mujer. Aunque, al igual que para el catolicismo, ambos sexos son complementarios.

\footnotetext{
* Doctora en Medicina e Investigadora en la Facultad de Bioética, Universidad Anáhuac México, México. Correo electrónico: mtarasco@anahuac.mx https://orcid.org/0000-0001-7312-9970

** Doctor en Filosofía por la Universidad de Navarra. Maestro en Gerontología Social. Profesor e investigador del CISAV, México. Correo electrónico: jegomezalvarez @yahoo.com https://orcid.org/0000-0002-8964-2207

Recepción: 22 de noviembre de 2019. Aceptación: 12 de enero de 2020
} 
Palabras clave: género, religión, cultura, vejez.

\section{Introducción}

Para poder entender cualquier cultura ajena a la propia, es indispensable entender la alteridad del otro, ya que, de no ser así, no se puede juzgar lo que se pretende. En China, la cultura ha estado impregnada de confucionismo y, por ello, se requiere conocer la idea cultural del mismo.

Esta intervención busca, desde la perspectiva católica, interpretar algunas de las consecuencias de la doctrina de Confucio respecto de la mujer. Debido a que la filosofía es una forma de vivir basada en la reflexión, ésta es la razón por la que en ese sentido se entrecruzan estos modos de presentar la reflexión filosófica.

A pesar de que el confucionismo es una enseñanza de mejoramiento personal, y de cuidado de las interrelaciones apropiadas, existe un hueco entre las enseñanzas morales de esta doctrina y la realidad histórica de la opresión de género en la China Imperial. Pero esto no difiere de la religión católica, y de tantas otras religiones, en las que en épocas anteriores la mujer también ha sido infravalorada en la práctica cotidiana, a pesar de que esto sea contrario a las enseñanzas evangélicas y del Magisterio. Por ello vale la pena valorar si la mujer llegaba a tener un papel activo en esta tradición.

El confucionismo suele ser interpretado en dos sentidos: primero, como la respuesta al desorden político y social de la época por las continuas guerras y querellas entre los señores feudales de la región. En este sentido no puede considerarse una religión, como Confucio mismo subrayó, sino solamente como una serie de normas de conducta moral que con la práctica se vuelven un hábito y, por ende, una virtud. Y segundo, como una filosofía aplicada o práctica, según la terminología moderna. 
Reflexiones éticas desde el confucionismo: la mujer

\section{Contenido doctrinal}

Se fundamenta en el reconocimiento de un orden cósmico, que considera perfecto, y que, como tal, debe ser imitado en la conducta humana. Por ello establece un código de conducta. Estas normas morales son tradicionales para la cultura china de la época imperial, por lo que fueron bien aceptadas.

Cinco pilares constituyen la inspiración del confucionismo: el altruismo, la tolerancia, el respeto mutuo, la armonía social y cumplir con el deber. A pesar de proponer la tolerancia, y quizá por el objetivo de intentar lograr un orden político, Confucio declara que todo gobernante debe ser moral y hacer el bien, y que la verdadera nobleza consistía en esta virtuosa moralidad, y no sólo en el origen de su nacimiento. Tal vez ésa fue la causa de su popularidad entre el pueblo, al mismo tiempo que de rechazo entre la nobleza, a la cual él mismo pertenecía. Por ello fue perseguido durante la dinastía Ts'in, pero durante la dinastía Han se convirtió en la filosofía oficial del Estado, hasta el inicio del régimen comunista, y posteriormente ha vuelto a tomar auge. A pesar de los vaivenes del confucionismo en la historia de China, no puede dejar de aceptarse que aún hoy se le considera como la base de la cultura, aunque el daoísmo y el budismo también lo son, pero el confucionismo prevalece con mayor fuerza..

Los cuatro libros de Confucio (Gran Saber, Doctrina de la Medianía, Analectas y Mencio) no fueron escritos por él directamente, sino que son recopilaciones de sus seguidores. Eso, como es obvio, dificulta el establecer con transparencia la doctrina auténtica del filósofo, ya que incluso hubo textos previos a su nacimiento que fueron incorporados. No obstante, es posible entresacar las ideas filosóficas acerca de la virtud, que pueden aplicarse al contexto de la mujer, así como los rituales de las actividades diarias en los que existen códigos de conducta que son propios de la mujer, y otros comunes a ambos sexos.

Medicina y Ética - Abril-Junio 2020 - Vol. 31 - Núm. 2 
Además, ha habido un resurgimiento del confucionismo en China, como se afirma en el artículo de Young Chen publicado por el Colegio de México sobre este tema, que lo explica por la observación de cuatro fenómenos:

«...la campaña de recitar los clásicos confucianos, ${ }^{1}$ el renacimiento de las academias confucianas, y la restauración de los ritos confucianos. ...[así como] ...el Jiang Qing, ....argumenta que las condiciones sociopolíticas y culturales de la China contemporánea han allanado el camino para el surgimiento de los movimientos tradicionalistas... [con la], combinación de filosofía fundamentalista de Jiang Qing y su autodisciplina estricta moral» (1) (Cheng, Y. 2013).

Como un ejemplo del resurgimiento de esta tradición, desde el 2010, por primera vez después de 100 años, ha habido celebración de bodas con ritos confucionistas antiguos, y se considera una forma de promoción para fortalecer el modelo familiar chino. Otro ejemplo es la ceremonia de estreno de los pinceles, como inicio de la escolaridad, que en la actualidad se considera una tradición del Estado, a pesar de provenir de la tradición confucionista.

Sin embargo, esta doctrina filosófico-«religiosa» ha sufrido cambios, particularmente en sus valores (2). El confucionismo resalta que no se castiguen las faltas, y que, en lugar de ello, se fortalezcan los valores a través de ritos, para que el individuo se avergüence de sí mismo cuando se comporta fuera de esta moral. Este resurgimiento de tipo costumbrista «religioso», difiere de los estudios confucionistas, que han sido parte del aprendizaje del Estado moderno. Además, en este siglo también se ha fortalecido en Taiwan. Este renacimiento también está relacionado con una especie de «protección o escudo» contra el cristianismo.

\section{El confucianismo como una filosofía}

Hay que precisar que el confucionismo también ha sido considerado como una filosofía aplicada. Es verdad que existen afirma- 
ciones metafísicas acerca del orden del mundo; sin embargo, éstas no son presentadas como dogmas que el creyente deba admitir. Es una doctrina ética fundada fuertemente en la virtud, con miras a mejorar al hombre individual y a la sociedad en su conjunto:

«La ley del Gran Estudio, o de la filosofía práctica, consiste en desenvolver y dar a luz el principio luminoso de la razón que hemos recibido del cielo, en renovar a los hombres, en situar su destino definitivo en la perfección o soberano bien» (3 Pos. 566).

Confucio reforzó la importancia de la familia tradicional en la sociedad china, al insistir en el respeto de los hijos a los padres y en la obediencia de las mujeres a sus maridos. También reforzó la sumisión del pueblo a las autoridades, aunque rechazando la tiranía: los súbditos debían obediencia al soberano, ya que el Estado existía para buscar el bien de los gobernados; pero, por lo mismo, los gobernantes debían gobernar según rectos principios éticos, aplicando el ejemplo moral y no la fuerza. Soñaba con el regreso a un pasado idealizado, en el que un emperador sabio y bondadoso (el «Hijo del Cielo») gobernara y fuera obedecido como un padre por sus hijos, en un clima general de paz y de orden. Asimismo, indica que la perfección, aunque es individual, debe incluir el perfeccionar también a los demás (3). Ello lleva a una paz interior en donde dirá: «...tener el espíritu tranquilo y sosegado, se puede prontamente gozar de ese reposo inalterable que nada puede turbar» (3 Pos. 571).

Sin duda recuerda a la posición del estoicismo en el mundo occidental. Así, por ejemplo, cuando Confucio afirma que el hombre superior no busca los placeres ni la ociosidad, y que busca mantenerse con principios rectos «a fin de regular su conducta». Un hombre tal puede ser llamado filósofo, o que se deleita con el estudio de la sabiduría» (3 Pos. 1256). Si esto se compara con la posición de Séneca, los parecidos o los enfoques son semejantes:

«...la filosofía... no está en las palabras sino en las obras. Ni ha de usarse para pasar el día con algún placer para quitar su fastidio a la ocio- 
sidad. Forma y modela el alma, ordena la vida, rige las acciones, indica lo que ha de hacerse y omitirse... Sin ella, nadie puede vivir sin temor» (4, Pos. 62).

El hombre sabio debe dirigirse con la razón y seguir la naturaleza de las cosas para así ser sabio (3). El estado de equilibrio es el control de las pasiones que, expresadas en un grado apropiado, constituyen la armonía. Para Confucio, la relación entre ambas constituye el camino ético.

\section{La mujer: alusiones en los textos}

Los textos de Confucio hacen pocas alusiones a la mujer directamente como parte de la aplicación de la filosofía. Pero, en cambio, en los ritos sí hay una clara diferenciación entre hombre y mujer. Sobre todo, se describe el papel social de ambos. A la mujer, le corresponde ser esposa o concubina y madre (menciona a la madre de ciertos personajes) (3). En total se encuentran 60 referencias a las mujeres, pero la mayoría son anecdóticas. Sin embargo, es verdad que Confucio considera a la mujer como persona que puede alcanzar los mismos logros que el hombre en lo que se refiere a la sabiduría; no obstante, la mujer sabia tiene menos presencia social que el hombre, y está sometida a él:

Kungtsé dijo: «los hombres de talento son raros y difíciles de encontrar; ¿no es esto verdad? A partir de la época de Chang (Yao) y de Yu (Chun), hasta estos ministros llenos de mérito, tan sólo ha habido una mujer, así como nueve hombres de mérito, y he ahí todo» (3, Pos. 1748).

En el confucionismo hay una clara indicación hacia los lazos familiares que pueden haber influido en la opresión a la mujer en la época pre moderna, como son la piedad filial vista como virtud, la continuidad del apellido y la veneración de ancestros del patriarca familiar, que requerían descendencia de varones. Por eso, el infanti- 
cidio de niñas se practicaba desde entonces, pero para guardar recursos para los varones.

Además, la mujer está subordinada a sus deberes de esposa y debe seguir las tradiciones de su tiempo (3). En el libro de los Ritos Liji, se establece que el matrimonio tiene el doble propósito de perpetuar el linaje, y de proveer al templo con los sacrificios para el matrimonio. En este libro se puede entender que la mujer tenía sólo un papel de funcionalidad. La mujer fuera del matrimonio no tenía ningún lugar en la sociedad, sin distinción de clases, de cultura o de edad

El hombre podía tener esposa legítima y concubinas. Y el papel que le otorgara a cada una no dependía de sus sentimientos, sino de la utilidad de las mismas para sus suegros. Es decir, que eran los padres del varón quienes tenían la preminencia sobre sus hijos varones y, aún más, sobre las mujeres de éstos. Las esposas de los hijos debían servir a sus suegros, del mismo modo como servían a sus propios padres (5). Sin embargo, se protege a los hijos de todas. En particular si eran queridas por los abuelos paternos.

Si los padres tenían un muchacho nacido de una sirvienta, o un hijo o nieto de una de sus concubinas, con quienes estaban muy encariñados, todos sus hijos debían, después de su muerte, perder el respeto hacia él.

Si un hijo tenía dos concubinas, una de las cuales era amada por sus padres, mientras que él amaba a la otra, no debía atreverse a convertir a ésta en igual a la anterior, a quien sus padres amaban, con vestidos, alimentos, o con los deberes que ella desempeñaba, ni tampoco debía disminuir sus atenciones hacia ella después de su muerte.

Si le gustaba mucho su esposa, pero a sus padres no les agradaba ella, debía divorciarse.

Si no le gustaba mucho su esposa y sus padres decían: «ella nos sirve bien», debía comportarse con ella con todos los respetos hacia una esposa, sin faltarle hasta el final de su vida (5, Pos. 39). 
Estos textos señalan siempre un trato digno a la mujer, aunque en el marco de las costumbres de la época. En el Libro IX, sección tercera, la indicación de la subordinación de la mujer es clara. Señala el texto:

«Debe haber sinceridad en los... matrimonios, y la comunicación con la mujer debe ser buena. Ella será amonestada para que sea recta y sincera. La fidelidad es indispensable en todo servicio hacia el otro; ...es la virtud de una esposa... [que] cuando el esposo muera no se casará de nuevo... es el hombre quien toma la iniciativa y no la mujer...» (5, Pos. 22).

Y un poco más adelante dice:

La mujer sigue y obedece al hombre. En su juventud, sigue a su padre y a su hermano mayor; cuando está casada, a su marido; cuando su marido muere, sigue a su hijo (5, Pos. 23).

Los hombres no debían hablar de lo que pertenece al interior de la casa, ni las mujeres de aquello que corresponde al exterior. Excepto en sacrificios y en ritos funerarios, debían pasarse los recipientes de unos a otros (5), no debían ir al mismo pozo, ni al mismo baño. No debían compartir la misma estera al acostarse; tampoco solicitar o pedir prestado cualquier cosa el uno al otro; no debían usar similar ropa superior o inferior (5).

En cuanto a las funciones, la piedad filial se considera como una virtud esencial del que aspira a ser sabio. Se insiste así en respetar a los padres (3, Pos. 1234, 1283, 1286, 1288, 1291), aun cuando ellos fallen como padres (3). Hay deber de no abandonarlos (3), realizar las ceremonias fúnebres adecuadas (3) y ambos progenitores deben tener ritos equitativos (3). Y el luto por ellos debe guardarse por tres años (3).

Es interesante ver que, cuando se habla del buen gobierno, se señala que debe ser como padre y madre del pueblo (3). 
En el Libro de los Ritos el trato a los ancianos era considerado desde el punto de vista de eliminar funciones que no tenían que seguir ya grandes, como el recibir alimentación y trato especial (5).

En cuanto a la educación, era claramente diferenciada. Por ejemplo, respecto de las mujeres se señala:

A la edad de diez años una muchacha dejaba de salir de los apartamentos de las mujeres. Su institutriz le enseñaba las artes del discurso y las maneras agradables; a ser dócil y obediente, a manejar las fibras de cáñamo, a tratar los capullos para tejer la seda y formar hilos, así como todos los trabajos de mujer; cómo confeccionar la ropa, observar los sacrificios, proveer los licores y las salsas, llenar los diferentes soportes y platos con conservas y salmueras, y asistir en la disposición de los accesorios para las ceremonias (5, Pos. 37). A los quince, asumía la horquetilla; a los veinte, estaba casada, aunque si había sido necesario retrasar el matrimonio, lo estaba a los veintitrés (5, Pos. 55).

El confucionismo, a pesar de ser una tradición cultural muy compleja, no tiene elementos de género, concebido con la idea occidental de la deconstrucción feminista. Sin embargo, hay hechos de costumbres chinas pre modernas, como la subyugación femenina (6), que sí están vinculados al confucionismo, y otras prácticas como el homicidio de niñas, o el matrimonio de niñas, que eran llevadas a casa de los suegros desde temprana edad para empezar a servir ahí, y el concubinato, que se aceptaba si la esposa original no lograba tener descendencia de varones, y que además era una de las siete causas por las que podía deshacerse el matrimonio.

Aunque es verdad que Confucio habla también de ciertos valores universales que implican respeto a la mujer. Así, Walker Vadillo apunta:

"Lealtad y reciprocidad. En todas las relaciones sociales confucianas, el principio de la humanidad debe ser medida de toda acción, que, a su vez, deberá ser correspondida con reciprocidad. Así pues, aunque la mujer esté en una posición de desigualdad frente al hombre, éste le debe respeto, generosidad, tolerancia, unas atribuciones muy distintas 
a la injusticia social que ha vivido la mujer en países neo-confucianos hasta hoy en día» (8).

El vendaje de los pies, que se usó como marca étnica de los Han, durante la invasión de Manchuria y las prácticas de fidelidad en la viudez, de los periodos Ming y Qing, en realidad no estaba directamente relacionado con el linaje. Pero la mujer viuda lo usaba como medida de protección, ya que una viuda continuaba siendo de la familia, pero a la vez podía tener más libertad para expresarse en la vida y en los trabajos públicos. En cambio, si se desvinculaba de la familia del esposo fallecido, se quedaba en un estado civil de «inexistencia».

\section{La vejez, la virtud y la mujer: reflexiones sobre un par de textos}

No obstante, Confucio menciona la necesidad de atender por parte del emperador a los más desfavorecidos, incluyendo ancianos y ancianas:

«Los ancianos que no tenían mujeres eran nombrados viudos...; la mujer de edad que no tenía marido era llamada viuda o sin compañero (kua)... Vanvang introduce en su gobierno los principios de equidad y de justicia y practica en todas las ocasiones la gran virtud de humanidad... El Libro de los Versos dice: "Se puede ser rico y poderoso; pero es preciso tener compasión para los desgraciados viudos y huérfanos"» (5, Pos. 3129).

Estos ejemplos hacen una clara referencia a dos factores: por un lado, a que cada sexo tenía muy diferenciado su rol social, y a que dentro de éste se respetaba a la mujer, aunque con subyugación jerárquica a la mujer de mayor edad. De nuevo, la vejez daba ciertas «ventajas» respecto a otros miembros sociales. Pero está claro que el varón tenía una clara prevalencia y la mujer, aunque fuera la madre, estaba supeditada a éste. 
Analizando algunos aforismos, se descubre, no obstante, que no hay diferencia de géneros en cuanto al trato o respeto a la virtud. Así se menciona que:

«1. Confucio dijo: "Si para guiar a los súbditos se usa del poder y para igualarlos de los castigos, el pueblo huirá de éstos, pero no se avergonzará de nada".

2. "Si para guiar a los súbditos se usa la virtud y para igualarlos los ritos, el pueblo tendrá vergüenza y, además, será honesto"» (9).

Aquí quizás puede inferirse el sentido de los ritos. Los mismos no son sólo ordenaciones externas, sino medios de dar orden y reglas de igualación, como sugiere la cita. No se trata de una imposición desde el más fuerte, de una «dominación patriarcal» diríamos hoy, sino de mostar o ser ejemplo en el bien, pero esto no implica igualación en automático en cuanto a la acción. La virtud se da, pues, en la diferencia de funciones puestas y unificadas por la virtud. Los ritos se convierten, así, en medio y no en fin de la acción política. No se trata de conservar ritos sin más, sino que estén orientados a dar un cierto puesto adecuado a cada uno. Puede objetarse que los ritos en sí mismos son viciosos por la subordinación indicada, pero al menos el espíritu de Confucio no lo plantea así. Un ejemplo pueden ser las diferencias de vestimenta o los ritos funerarios. Aun en Occidente consideramos que los ritos asociados a los mismos nos sirven para «saber cómo comportarnos como iguales entre diferentes». Los ritos no son mecanizaciones sin más, ya que el mismo Confucio señala que «aprender sin pensar es inútil; pensar sin aprender es peligroso» (B). Los ritos sociales que diferencian a los hombres y mujeres en esa óptica se aprenden para poder igualar a todos; es decir, deben ser practicados y aceptados por las distintas personas, pero comprendidas en su sentido, y que sólo si se reproducen, entonces ahí sí pueden verse como coaccionadores de la libertad sin más.

Confucio señala en sus libros que la vejez es un culmen desde la sabiduría (9), ya que ahí se armonizan las pasiones. Él no realiza 
ninguna distinción de género. Otro ejemplo: al referirse al gobierno del rey Wen (que gobernaba Qi), Confucio no distingue en el grado de atención entre los viudos y viudas del reino (9).

En cambio, al instaurarse la República Popular China, se tomó como reivindicación la discriminación a la mujer. Se purgó a China del confucionismo, por considerar que la gente, en particular la mujer, se visualizaba como inferior. Así, con el Cuarto Movimiento de Mayo y la Revolución Cultural Comunista, la mujer entra a la modernidad (años 70s) y a la comunidad internacional (6). Simultáneamente, en el mundo se fraguaba el boom del movimiento feminista, al que China se sumó (10). En oros países, como Japón, siguiendo las ideas confucionistas, se genera un respeto a las mujeres ancianas como parte de la piedad filial ya indicada, en donde conviven las generaciones entre sí como parte del respeto filial (11). No obstante, es un tema que merece más espacio. Lo que aquí se ha querido mostrar son los elementos conceptuales que aparecen en Confucio y que podrían provocar un debate en materia de género, con variables tales como la vejez.

\section{Conclusiones}

La familia patriarcal, como parte de la cultura china, no significa que la mujer se considerara a sí misma como víctima, sino que culturalmente era parte de la transmisión cultural y su papel social estaba muy marcado. Obviamente desde la óptica occidental, se percibe en forma opuesta. Concretamente, al catolicismo se le ha criticado, desde la óptica del feminismo de género, que a la mujer se le «someta» a ser madre, esposa..., aunque no sea una obligación serlo, como bien lo sabemos, pero para el catolicismo el reconocer la diferencia sexual biológica y cultural, no es motivo de lamentación, ni de opresión.

La mujer occidental se ve a sí misma independiente para establecer los lazos que desee. Mientras que la mujer china premo- 
derna se veía a sí misma como dependiente de los lazos familiares. Sin ellos estaría en una grave situación de vulnerabilidad, al no tener parentesco con nadie. En el catolicismo, la mujer tiene igual dignidad que el hombre y, al igual que éste, es libre. Sin embargo, ambos están llamados a la santidad, a través de la realización de la voluntad de Dios, y los estados de vida, son una vocación o llamado, en los que la persona se realiza en plenitud, al entregarse, en el caso del matrimonio, por amor a Dios, a su cónyuge y a los hijos.

En el confucionismo, es la relación de parentesco la que logra el género de la mujer. Aunque, al igual que para el catolicismo, ambos sexos son complementarios. En el confucionismo es a través del Ying-Yang, pero con mayor énfasis lo es a través de las esferas de acción: lo privado y lo público. No es que la mujer no pudiera recibir instrucción, sino que su papel estaba enfocado a la familia (nei), más que a la esfera externa, ya que la familia es el fundamento sobre el que se construye un estado armonioso. Por ejemplo, la virtud «privada» de piedad filial es el tronco común para todas las virtudes «públicas», y así es una forma de complementación, también en la acción.

Aunque se ha mostrado a la mujer china como sumisa, analfabeta y oprimida, existen textos en donde ellas mismas escriben una realidad diferente en cierta medida. La educación formal en la antigüedad se adquiría en las clases sociales altas, pero, en cambio, el poder femenino era común a todas las esferas, sólo que siempre supeditado al parentesco: la hija estaba sujeta a sus padres, y después al marido y a los suegros. Pero cuando ella se volvía suegra, las hijas y nueras lo estaban a ella. Hay ejemplos en la literatura de mujeres hábiles en el arte de la discusión, de la argumentación, de la sabiduría, etc., y que eran capaces de enseñar a sus hijos e hijas sus papeles en el mundo. A pesar de que muchas mujeres publicaron obras literarias, sin embargo no tuvieron acceso al Wei o cargos públicos, para poner sus talentos al servicio del Estado.

La disparidad entre Wei y Nei pone de manifiesto la diferencia y subyugación entre hombres y mujeres en la China premoderna. Sin 
embargo, en el confucionismo moderno, el género adquiere la visión cultural occidental, sólo que basado no en la elección autónoma propiamente dicha, sino en los lazos de parentesco que se establezcan.

Las referencias a los Cuatro Libros nos muestran la necesidad de vivir en el respeto de todos con todos, sin eliminar las diferencias sociales entre sus miembros. Por supuesto, un estado de cosas que Confucio no creó, pero que consideró adecuado preservar en un marco de virtud.

\section{Notas bibliográficas}

1 Se hace en temprana edad escolar hasta la primera adolescencia, para que aprendan los niños a aceptar la doctrina moral, más rígida, que las nuevas costumbres actuales.

\section{Referencias bibliográficas}

(1) CHENG, Y. El reciente resurgimiento del confucionismo popular en China continental: el redescubrimiento de los confucianistas clásicos, las academias y los ritos. Estudios de Asia y África. [internet] 2013. [Consultado 23 Nov 2019]; (I) 1; Disponible en: https://estudiosdeasiayafrica.colmex.mx/index.php/eaa/article/view/ 2194 https://doi.org/10.24201/eaa.v50i1(156.2194

(2) Levenson, J. Confucian China and its Modern Fate: The Problem of Intellectual Continuity, Berkeley-Los Ángeles: University of California Press; 1968.

https://doi.org/10.1086/ahr/72.2.668

(3) Confucio. Los cuatro libros de Confucio. Trad. de Juan Bautista Bergua. Madrid: Ediciones ibéricas-La crítica literaria; 2010.

(4) SÉnECA, L. Cartas a Lucilio. México: SeP; 1985.

(5) LIJING, Tratado de los ritos Vol. II (LIBROS IX- XVIII) Traducciones de FuLVIO SCARCIA, LEONARDO LA RosA, JULIO LÓPEZ SACO. Madrid: Univesidad Carlos III; 2009 [Consultado 7 Dic 2019]. Disponible en: https://www.academia.edu/ 18424415/Lijing._Tratado_de_los_Ritos._Vol_II_Libros_IX-_XVIII_ https://doi.org/10.5944/etfvii.24.2011.1407

(6) LITTLE JOHN, L. Confucianism: How Analects Promoted Patriarchy and Influenced the Subordination of Women in East Asia. Young Historians Conference; 
Reflexiones éticas desde el confucionismo: la mujer

2017, 9. [Consultado 14 Oct 2019] Disponible en: http://pdxscholar.library. pdx.edu /younghistorians/2017/oralpres/9

(7) CRosby, Bruce. Never Disobey': How Confucian Filial Piety Is Counterproductive to Its Goals for Society? Armstrong Undergraduate Journal of History [Internet]. 2019. [Consultado 10 Dic 2019] (9) 1. Disponible en: https://digitalcommons. georgiasouthern.edu/aujh/vol9/iss1/8/ DOI: 10.20429/aujh.2019.090108 https://doi.org/10.20429/aujh.2019.090108

(8) WALKeR, V. Analectas en Femenino: una crítica de género al texto de Confucio. [internet]. Pensamiento y Religión en Asia Oriental; 2009 [Consultado el 20 Dic 2019] Disponible en: https://www.academia.edu/355219/Analectas_en_ Femenino_Una_crítica_de_Género_al_Texto_de_Confucio.

https://doi.org/10.1353/ntc. $1994.000 \overline{7}$

(9) S.A. Pensamiento Chino. Textos. [internet].Universidad de Granada; s.f. [Consultado el 20 Ene 2020] Disponible en: https://www.ugr.es/ psgines/Docencia/ PensChino/PensChiTextos.pdf

(10) JIJI. LA representación de las mujeres en el cine chino contemporáneo y la Influencia del pensamiento de Confucio. [Doctor]. Carlos III; 2016.

(11) JORDAN, N. Comparative analysis of intergenerational solidarity programs in Spain and Japan. [Grado]. Universidad Autónoma de Madrid; 2019. 
